\title{
NATURE
}

\section{Who Should be Tracked Hovercruff's Heir?}

THE Select Committee on Science and Technology has yet to unravel the full mystery associated with the decision taken earlier this year to close down Tracked Hovercraft Limited. Ever since the decision to abandon work at the Earith base of the company was announced, most unfortunately at a time when the select committee had just decided to investigate the future of the project, $\mathrm{Mr}$ Airey Neave and his committee have apparently left no stone unturned in their quest for the reasons behind the decision. But, as last week's hearings showed (see page 180) the committee still feels that there is more to be learnt and although its attempts to obtain the minutes of meetings held in the summer and autumn of 1972 might meet with stiff resistance $\mathrm{Mr}$ Neave and colleagues will certainly not rest until they are satisfied they know all the facts.

One uncertain aspect of the decision to stop further financial support for the hovertrain is who carried out an appraisal of the company before the final decision was taken. Last week both the chief scientist at the DTI, Dr Ieuan Maddock, and the Director General of Research at the Department of the Environment, Mr D. J. Lyons, did not, in the eyes of the select committee, provide a satisfactory answer to this question. Mr Neave's whimsical aside, on whether it will ever be known who evaluated the future prospects of the company summed up the present situation admirably. But the important aspects of the present inquiry are not solely concentrated around this issue. The deed is done and the decision taken in February to preserve the linear motor work of Tracked Hovercraft Limited through a contract with Hawker Siddeley Dynamics, the precise details of which have still to be determined, needs careful consideration.

According to the government, there is no future for an inter-city transport system based on the tracked hovercraft principle in Britain before 1985, and only limited possibilities between then and the end of the century. It is hard to argue with this although there are some who would say that British Rail should not be basing its future policy solely on the steel wheels on steel rails principle. But it is this conclusion which spelled the end for THL.

But unfortunately the decision did not turn out to be as simple as that and two factors have clouded the issue. First, the decision of the DTI to preserve the work carried out by the company of linear motors and, second, the fact that at the time of the decision to stop supporting THL, the company, in conjunction with Hawker Siddeley, were bidding to build a transit system for the Ontario Government in Toronto.

In the past few weeks both these explanations have been put forward as the rationale for the Department of Trade and Industry's decision to grant $£ 500,000$ to Hawker Siddeley to pursue work on linear motors and, unfortunately, both explanations leave something to be desired. Britain, primarily through the efforts of Professor E. R. Laithwaite at Imperial College, is in the forefront of research in linear motors, and it is proper that development work on linear motors should continue. But is Hawker Siddeley the right company for this? Hawker Siddeley has a redoubtable reputation in the fields of transport and the management of large projects, but palpably no experience of linear motors design and construction. If the object was now to go ahead and build a transport system based on linear motors then there would be little argument that the correct company had been chosen. But the object of granting money to Hawker Siddeley, according to the DTI, was to preserve the research work undertaken by THL on linear motors. A strange decision-if this was the only motive behind it-a company with experience in linear motors would clearly have been a more suitable choice. But it is now abundantly clear that preserving the linear motor research of THL was not the chief reason why Hawker Siddeley was chosen to be the beneficiary of the DTI's generosity. And it was the need for the combined Hawker Siddeley and Tracked Hovercraft Limited bid for the Ontario contract to still have credence after THL ceased operations that led to the DTI's actions.

The DTI is now in an awkward situation. Hawker Siddeley, as luck has it, unfortunately failed to win the Ontario contract-not, as Dr Maddock said last week, because of the demise of THL but because it clearly overbid on the civil engineering side. But the company can still look forward to $£ 0.5$ million of government money.

It is now time for the DTI to show that it is really serious about preserving the THL work on linear motors by looking to other companies which have had some previous experience with these motors. It is indeed fortunate that the arrangement with Hawker Siddeley still leaves the DTI open to place contracts elsewhere, and one of the pleasing aspects of last week's hearing was the announcement by Dr Maddock that his department is also talking to GEC, a company with some experience of linear motor work. This will be a more sensible way to proceed now that it is clear why Hawker Siddeley was chosen in the first place. What will indeed be of interest will be the terms of the contract between the Department of Trade and Industry and Hawker Siddeley when they are finally settled.

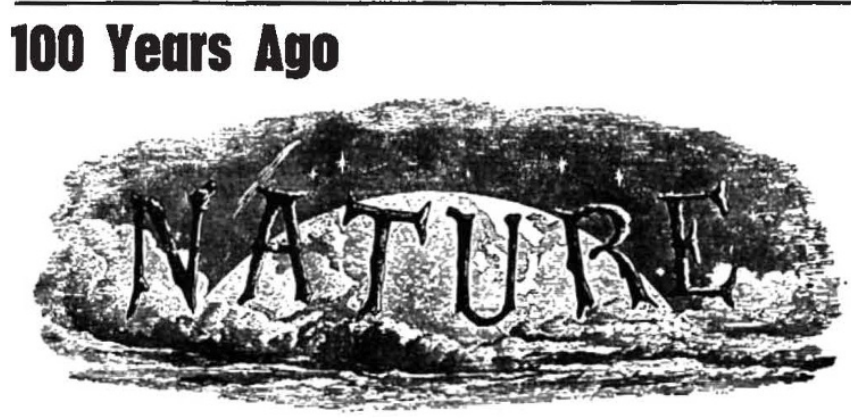

AT the special request of Rear-Admiral Sands, the U.S Congress, at its last session, allowed an appropriation for the purpose of completing and publishing the catalogue of southern stars, observed by Gilliss in 1850-52, and the work is now being put in the hands of computers for publication as soon as possible.

From Nature, 8, 94, May 29, 1873 